\title{
Mediação da informação e mediação pedagógica na pesquisa escolar
}

\author{
Mediation of information and pedagogical mediation in school search
}

Edson Silva Ferreira

Bacharel em Biblioteconomia pela Universidade Estadual de Londrina - UEL.

E-mail: edsonjapones@ hotmail.com

João Arlindo dos Santos Neto

Doutorando em Ciência da Informação pela Universidade Estadual Paulista "Júlio de Mesquita Filho" - UNESP, campus de Marília.

Professor do Departamento de Ciência da Informação da Universidade Estadual de Londrina - UEL.

E-mail: santosneto@uel.br

\section{Resumo}

Apresenta conceitos e definições sobre mediação da informação e mediação pedagógica, a partir de um referencial teórico. Este artigo tem como objetivo discutir a relação entre a mediação da informação e a mediação pedagógica na biblioteca escolar. A pesquisa buscou analisar como ocorrem essas mediações com os alunos do ensino médio. Seu desenvolvimento foi por meio da pesquisa básica e exploratória, com abordagem quali-quantitativa. Foi aplicado um questionário aos alunos e aos professores de uma escola estadual no interior do Paraná. Acredita-se que professor e bibliotecário, em igual nível de importância, podem contribuir com a pesquisa escolar dos alunos. Revela que esses profissionais apesar de terem consciência de que o trabalho em conjunto contribui de forma significativa para o ensino e educação, ainda deixam a desejar. Conclui que apesar do discurso existente entre os profissionais e o presente na literatura sobre a importância de mediação e o trabalho em conjunto na biblioteca escolar e, especificamente, na pesquisa escolar, ainda não é o que acontece na maioria dos espaços.

Palavras-chave: Mediação da informação. Mediação pedagógica. Pesquisa escolar. Biblioteca escolar.

\begin{abstract}
Presents concepts and definitions of mediation information and pedagogical mediation, from a theoretical framework. This article aims to discuss the relationship between mediation information and the mediation in the school library. The research sought to examine how these mediations occur with high school students. Its development was through basic and exploratory research, with qualitative and quantitative approach. A questionnaire was applied to the students and teachers of a public school in the state of Paraná. It is believed that teacher and librarian, in the same level of importance, can contribute to scholarly research of the students. Reveals that these professionals despite being aware that working together makes a significant contribution to teaching and education, still fall short. Concludes that despite the existing discourse among professionals and in the literature about the importance of mediation and working together in the school library, and specifically in scholarly research, it is still not the case in most areas.
\end{abstract}

Keywords: Mediation of information. Pedagogical. Mediation. Scholarly research. School library. 


\section{Introdução}

Com a disponibilização das informações de forma constante e cada vez mais rápida, aumenta-se também a procura por fontes de conhecimento e informação através das pesquisas, sejam estas escolares ou científicas.

No âmbito das pesquisas e dos trabalhos escolares, pode-se destacar que são muitas as escolas com falta de bibliotecas para proporcionar o devido subsídio na realização das pesquisas escolares e real contribuição no aprendizado de seus alunos.

Da mesma forma, ocorre a falta de bibliotecários para orientar os alunos, quanto ao tipo de materiais bibliográficos e recursos disponíveis que poderão ser utilizados em suas pesquisas. Acredita-se que para que ocorra a utilização de fontes de informação confiáveis, é necessário que elas sejam mediadas e apresentadas, fazendo com que os alunos desenvolvam trabalhos e pesquisas escolares com maior fidedignidade e qualidade, consequentemente aumentando o interesse na busca de conhecimento pelo aluno.

A pesquisa escolar (PE) tem a capacidade de não somente promover o ensino como também de contribuir para os procedimentos que são utilizados no ensino. Ela, necessariamente, deveria fazer parte de todo o percurso educacional do aluno, pois estimula a sua criatividade e a curiosidade (ELLWEIN, 2006).

Com o uso do computador e da internet, realizar pesquisas e trabalhos escolares tem ficado cada vez mais "fácil". Os alunos encontram as informações de temas variados com facilidade, a partir de um clique em algum buscador da web. Diante disso, muitos deles acabam transcrevendo trechos prontos das páginas da internet e, até mesmo, realizam cópia literal do assunto pesquisado. Esta prática é realizada no percurso formativo inicial do aluno, mas em alguns casos, continua também no ensino superior.

Além disso, parte das pesquisas e trabalhos escolares realizados pelos alunos, em especial os do ensino médio, são estruturados de forma desorganizada, sem atentar-se para as questões formais de um trabalho acadêmico, isto é, uso de citação e referências, normalização etc.

Nesse sentido, percebe-se a importância de bibliotecários e professores mediarem a pesquisa juntos e de forma integrada, com o intuito de criarem condições e estratégias de ensino para que alunos/aprendizes alcancem resultados positivos no desenvolvimento da PE. Portanto, 
Edson Silva Ferreira e João Arlindo dos Santos Neto

é essencial que aluno, professor e bibliotecário percebam que a existência da biblioteca escolar (BE) é de fundamental importância.

A pesquisa buscou analisar e discutir como ocorrem essas mediações com os alunos do ensino médio. Seu desenvolvimento foi por meio da pesquisa básica e exploratória, com abordagem quali-quantitativa, e a coleta de dados foi realizada por intermédio de questionários aplicados aos alunos e professores de um colégio estadual na cidade de Londrina/PR.

\section{Biblioteca Escolar}

O conceito de biblioteca escolar ainda é, para alguns, um mero local onde se guarda livros. Porém, sabe-se que essa concepção é errônea; precisa e deve ser mudada. Em texto publicado pela IFLA/UNESCO (2002) já era elucidado que a BE, espaço de informação e conhecimento, propicia aos estudantes ideias fundamentais para sua convivência em sociedade e contribui para a formação deles como cidadãos, bem como possibilita o desenvolvimento da imaginação.

A BE tem dentre suas funções subsidiar os objetivos da escola para que juntas desenvolvam um trabalho de excelência. Ela desempenha papel fundamental na formação dos alunos, proporciona o contato e o acesso a diferentes materiais de leitura, como também cumpre um papel social que valoriza a informação e a cultura. Na ambiência da BE são desenvolvidas competências e habilidades para a aprendizagem ao longo da vida escolar.

\footnotetext{
Pesquisas recentes relacionadas à educação mostram que bibliotecas escolares de diversos países têm hoje papel que vai muito além de um espaço de promoção de leitura; elas são, principalmente, espaços de aprendizagem. Mas tal espaço deve ser adequado a esse propósito, e os bibliotecários precisam realizar ações mais efetivas na orientação dos estudantes, assim como no aperfeiçoamento de práticas escolares dentro das bibliotecas. (CAMPELLO, 2012, p. 7).
}

Nesse ambiente, o bibliotecário assume uma posição importantíssima no que diz respeito à mediação das pesquisas e trabalhos escolares, fornecendo instrução no momento da busca por fontes de informação, bem como na orientação de como estes trabalhos deverão ser realizados.

Para que uma biblioteca alcance seu papel educacional e informacional a presença do bibliotecário é fundamental. Objetivando que isso aconteça de maneira eficaz faz-se necessário que cada escola possua uma biblioteca. Portanto, existem iniciativas que possuem o intuito de 
Mediação da informação e mediação pedagógica na pesquisa escolar

substituir as bibliotecas escolares por salas de leitura, como é o caso do Governo do Estado de São Paulo.

Segundo o Programa Nacional Biblioteca da Escola, as salas de leitura em sua maioria não são apropriadas para as práticas de leitura, funcionam em espaços improvisados, dispõem de acervo com número reduzido, permanecem fechados durante alguns turnos do dia e são gerenciados por profissionais não capacitados (BRASIL, 2008).

Esses espaços ao substituírem as bibliotecas faz com que não haja a contratação de um bibliotecário, e costuma-se dar a responsabilidade desse ambiente a um professor readaptado da escola. Esse fato demonstra descaso em relação à biblioteca escolar e uma consequente desvalorização por parte dos alunos.

Percebendo a importância da biblioteca nesse cenário, o Conselho Federal de Biblioteconomia (CFB) e os Conselhos Regionais de Biblioteconomia (CRB's) que juntos formam o SISTEMA CFB/CRB elaboraram um projeto de âmbito nacional visando promover maior qualidade no ensino público no país, por meio da biblioteca escolar. Em 2008, por exemplo, elaboraram um projeto de Lei e o encaminharam para a Câmara Federal. O projeto tem como objetivo geral a proposta de que todas as escolas possuam uma biblioteca.

Após apreciação e análise do referido Projeto pelo Senado Federal, ele tornou-se Lei, sendo sancionada por Luiz Inácio Lula da Silva, Presidente da República em exercício na época. A Lei $\mathrm{n}^{\circ}$ 12.244, de 24 de maio de 2010 dispõe sobre a universalização das bibliotecas nas instituições de ensino do país. Em seu artigo primeiro declara que: “Art. 10 As instituições de ensino públicas e privadas de todos os sistemas de ensino do País contarão com bibliotecas, nos termos desta Lei" (BRASIL, 2010). A partir dessa Lei, entende-se que toda escola até o ano de 2020 deverá ter uma biblioteca.

O Sistema CFB/CRB (2008) compreende que as ações projetadas pela BE devem ser convergentes com: o contexto da escola, o projeto pedagógico e a cultura dela. Sendo necessário analisar a realidade desse ambiente específico, para prospectar formas alternativas de práticas e, possivelmente, ultrapassar as barreiras e dificuldades, como também para alcançar os objetivos almejados pelo projeto pedagógico da escola.

Entende-se como louvável que cada escola possa contar com a sua biblioteca. Diante disso resulta-se também a importância de um bibliotecário em cada BE. A presença desse profissional é fundamental, principalmente num momento em que a tecnologia, particularmente 
Edson Silva Ferreira e João Arlindo dos Santos Neto

computadores conectados à internet, permite o acesso a uma variedade de fontes de informação. Além de manter uma biblioteca organizada e de fazer empréstimos de livros, o bibliotecário realiza a mediação na biblioteca escolar.

A presença atuante de um bibliotecário nas BE's propicia qualidade e confiabilidade nos trabalhos e pesquisas escolares, realizados pelos alunos. Deste modo percebe-se a biblioteca depende da ação dele e de seu conhecimento para atender às necessidades dos alunos (TAVARES, 1973).

Com a presença das tecnologias de informação e comunicação (TIC), os usuários têm se tornado cada vez mais autônomos, e isso também vem acontecendo nas BE's. No entanto as TIC não excluem a necessidade da interferência do mediador, professor ou bibliotecário.

Ainda que alguns alunos tenham se tornado cada vez mais autônomos, a presença de um bibliotecário é indispensável. No relacionamento bibliotecário e aluno, Bortolin (2006, p. 71) defende que

[...] este profissional além de respeitar as características e necessidades dos usuários de hoje, deve estabelecer limites, sem autoritarismo, para que a criança e o adolescente possam ter, não apenas livre acesso as estantes, mas também espaços de liberdade para imaginar, indagar e inquietar, maravilhando-se com suas descobertas.

Há ainda uma concepção passiva e até negativa do bibliotecário e da BE, o ambiente é visto como local de punição para que o aluno seja "castigado", ou seja, o aluno relaciona o castigo com a ambiência da biblioteca, construindo uma imagem negativa deste ambiente.

A BE como um ambiente agradável e atraente, não geraria repulsa nos alunos. Sabe-se que alguns professores ainda possuem essa "cultura" de encaminhar o aluno que não fez a lição ou que está tumultuando a aula, para a biblioteca, seja para desenvolver alguma atividade ou somente "ficar de castigo". Por outro lado, reconhece-se a iniciativa de professores e bibliotecários que atuam de forma integrada e já transformaram a imagem da BE.

O ideal seria que aquela prática punitiva não ocorresse e que bibliotecário e professor utilizassem o ambiente da BE para desempenhar um trabalho em conjunto, de conscientização do quanto ela pode oferecer e contribuir para a formação dos alunos.

Vale ressaltar a iniciativa de alguns bibliotecários escolares que têm desempenhado mediações que fazem com que o "tempo do castigo" seja transformado em momentos prazerosos de aprendizagem e construção de conhecimento, fazendo com o que os alunos queiram permanecer na BE.

Bibl. Esc. em R., Ribeirão Preto, v. 5, n. 2, p. 1-18, 2016. 
Mediação da informação e mediação pedagógica na pesquisa escolar

Percebe-se que o bibliotecário escolar é um mediador de informações entre alunos e suas necessidades e, acima de tudo, permite que esses alunos construam conhecimento através de sua mediação, reconhece-se nessa relação, a possibilidade de atuação também do professor, elemento fundamental nos processos de formação social e aprendizagem dos alunos.

Uma hipótese é a de que as atividades que são desenvolvidas em sala de aula não incentivam os alunos no uso da BE como um espaço para orientação e contribuição em suas atividades. Justificando esse aspecto acredita-se que, "[...] se o professor de determinada disciplina percebe claramente as habilidades dos alunos para usar a biblioteca e a informação, será capaz de distribuir-lhes tarefas que requerem a utilização destas habilidades" (KUHLTHAU, 2002, p. 233).

Segundo a autora, é necessário que o professor reconheça as habilidades e as competências necessárias para o desenvolvimento de determinadas atividades. Como é o caso da pesquisa escolar, quando os alunos vão até a biblioteca em busca de material para copiar e não com o intuito de realizar uma pesquisa escolar de fato. Nas salas de aulas, em sua maioria, a conscientização e a instrução sobre a pesquisa escolar não é realizada atentando-se a todas as especificidades que envolvem essa atividade, ou seja, raramente discute-se a questão do plágio, da indicação da fonte, do aspecto formal do trabalho acadêmico, entre outros. Solicita-se ao aluno uma pesquisa sobre determinado tema e só, muitas vezes, não é apresentado aos alunos a importância da pesquisa escolar na vida deles e, menos ainda, ocorre a instrução para a realização desta atividade.

A BE oferece uma diversidade de materiais que enriquecem a aprendizagem de muitos conteúdos pelos alunos. Campello (2009) afirma que os bibliotecários entendem que a BE serve de modelo para crianças e jovens utilizarem e usufruírem outros espaços informacionais semelhantes ao longo de sua vida. Como por exemplo, museus, teatros, galeria de artes etc.

Os bibliotecários, desde que envolvidos e comprometidos com a educação e com seu papel social e pedagógico, desenvolvem um trabalho especial nas bibliotecas, atuando na mediação da leitura, do ensino e orientando os aprendizes em suas pesquisas e trabalhos escolares. É necessário um trabalho em conjunto entre professor e bibliotecário, pois acreditase que essa mediação é mais proveitosa e colaborativa sendo feita dessa maneira.

Biblioteca e escola devem se unir para alcançar a mesma finalidade: aguçar o pensamento crítico e criativo do aluno. O bibliotecário ou professor, ao desenvolverem um 
Edson Silva Ferreira e João Arlindo dos Santos Neto

trabalho voltado ao ensino que não esteja somente atrelado a grade curricular ou a medidas avaliativas, agindo de forma mediadora e buscando interagir de maneira a propiciar aos alunos um conhecimento além do adquirido em sala de aula, faz com que seu trabalho passe a ser reconhecido, bem como contribui de forma significativa com o meio educativo e social.

\section{Mediação da informação e mediação pedagógica}

Mediação da informação e pedagógica são, ou deveriam ser, práticas recorrentes na BE. A primeira pode ser entendida como a interação entre o bibliotecário, o aluno e sua necessidade informacional. A segunda, como a relação entre o professor, o conteúdo ministrado e o aluno. Em ambas ocorre a interferência do profissional que está à frente da mediação, pois tudo o que ele faz, ou se espera que faça, é pensando na necessidade de um sujeito, neste caso o aluno.

Segundo Almeida Júnior (2015, p. 25), a mediação da informação é:

Toda ação de interferência - realizada em um processo, por um profissional da informação e na ambiência de equipamentos informacionais -, direta ou indireta; consciente ou inconsciente; singular ou plural; individual ou coletiva; visando a apropriação de informação que satisfaça, parcialmente e de maneira momentânea, uma necessidade informacional, gerando conflitos e novas necessidades informacionais.

Compreende-se que a mediação da informação deva se dar em um processo e no espaço, não necessariamente físico, do equipamento informacional, atentando-se para a apropriação da informação que poderá ser feita pelo usuário. Essa mediação pode ser realizada por um dos profissionais da informação, porém nesse artigo refere-se ao bibliotecário escolar.

De acordo com Gomes (2014) a mediação da informação possui quatro dimensões: dialógica, estética, formativa e ética. Dialógica, pois a mediação só se dá no diálogo, na troca, na existência de conflitos. É estética quando se preocupa com a recepção que será feita na mediação, cuidando do espaço e do ambiente que ocorrerá o encontro com a informação. Formativa a partir do momento que todo processo mediativo o sujeito "significa e ressignifica", pois o retira da zona de conforto e o faz (re)pensar seus atos. Por fim, ética, na mediação lidase com sujeitos e situações específicas, interfere-se na vida deles e, portanto, requer uma postura que se preocupe e reconheça o sujeito no espaço relacional.

Almeida Júnior (2008) apresentou duas possibilidades de mediação da informação, uma implícita e a outra explícita. A primeira é quando o ato mediativo ocorre sem a presença do usuário, ou seja, no desenvolvimento de coleções, no processamento técnico, nas atividades de 
Mediação da informação e mediação pedagógica na pesquisa escolar

conservação e restauração etc. A segunda por outro lado, exige a presença (física ou virtual) do usuário, como nos serviços de atendimento ao usuário, entrevista de referência, normalização do trabalho acadêmico, indicações de leitura etc.

Após apresentar e discutir brevemente o conceito de mediação da informação, direciona-se a presente discussão para a mediação pedagógica. Nessa mediação, o professor é o mediador, com o intuito de promover formas e métodos para que o aluno realmente se aproprie do conteúdo socializado em sala de aula. A escola é percebida como um local onde o seu propósito é ensinar e educar, num processo formativo e dialógico, distante da concepção de educação bancária refutada por Paulo Freire, segundo o autor é preciso "saber que ensinar não é transferir conhecimento, mas criar as possibilidades para a sua própria produção ou a sua construção" (FREIRE, 2011, p. 47).

Acredita-se que o mundo da escola é o mundo dos saberes: saber cultura, saber ciência, saber experiência, saber modos de agir, entre outros (LIBÂNEO, 2002). É inegável que a escola tem importância social fundamental, sobretudo quando, através de seus professores e educadores, desenvolve trabalhos interferindo de forma intencional no aprendizado dos alunos.

Na mediação pedagógica o educador preocupa-se com a relação do aprendiz com o saber, mediando o caminho do aluno entre a ignorância e o conhecimento (DAVALLON, 2007). Junto aos seus educadores a escola trabalha com o intuito de assistir seus alunos não só para que estes alcancem sua aprendizagem em sala de aula, mas também de forma significativa para que através do que foi apreendido venham formar-se cidadãos para a vida, além dos muros da escola.

A mediação pedagógica direciona o processo de ensino e aprendizado para um trabalho em conjunto, beneficiando a pesquisa, a criatividade e, principalmente, o diálogo entre professor e aluno, cooperando, dessa forma, para a ampliação de habilidades e competências no mesmo. "[...] mediação fomenta no mediador, o sentimento de acolhimento para com o mediado e, neste a da reciprocidade. Sem esse acolhimento, não se estabelece a relação, condição central no processo de mediação" (SOUZA; DEPRESBITERIS; MACHADO, 2004, p. 56).

Retornando ao pensamento de Gomes (2014) já mencionado neste artigo, infere-se que na mediação estão presentes as relações afetivas e estéticas, isto é, quando um indivíduo se coloca entre ou no lugar do outro. O conceito de mediação pedagógica, portanto, está imbricado 
ao pensamento de uma ação concretizada com a ajuda do outro. No contexto escolar, o professor constitui-se em sujeito essencial, capaz de fazer um elo entre aquilo que o aluno já sabe e o que ele virá a aprender (MASSETTO, 2000).

Ainda de acordo com Masetto (2000) a mediação pedagógica significa o posicionamento e o comportamento do professor que se coloca como um facilitador, instigador ou motivador da aprendizagem, que ativamente colabora para que o aluno/aprendiz consiga alcançar seus objetivos. Vislumbra-se, portanto, um papel ainda mais importante do professor, visto que considerá-lo como um facilitador é reduzir o seu potencial de mediador. No processo mediativo pedagógico, o professor é condição sine qua non. No entanto, acredita-se também que essa mediação possa ser realiza em conjunto com outros profissionais da escola, como o bibliotecário.

$\mathrm{Na}$ relação presencial, pode-se dizer que é o professor que atua como mediador pedagógico entre o conteúdo e a aprendizagem por parte dos alunos. Mas diante da complexidade da ação docente, professores e demais profissionais comprometidos com a prática pedagógica, precisam de capacitação e formação continuada para acompanhar as constantes transformações do mundo contemporâneo. Dentre os profissionais comprometidos com a prática pedagógica destaca-se uma vez mais o bibliotecário.

Esse profissional torna-se um aliado do professor, por exemplo, quando sugere diferentes formas de fazer a pesquisa escolar (PE) utilizando uma estratégia eficiente, compartilhando experiências e dividindo responsabilidades com relação à aprendizagem dos estudantes (CAMPELLO, 2009).

\footnotetext{
A função pedagógica do bibliotecário pode ser ampliada, portanto, para incluir ações além da promoção da leitura, ao tornar visível o potencial da biblioteca na aprendizagem, não por meio de discursos idealistas e sedutores, mas de evidências que comprovem claramente como a aprendizagem por meio da biblioteca pode influir na qualidade dos resultados escolares. (CAMPELLO, 2009, p. 51).
}

Quando a autora afirma que o bibliotecário desenvolve ações, acredita-se que tais ações na biblioteca escolar incluem a mediação nas pesquisas escolares. O bibliotecário é um mediador que interfere na relação escola/biblioteca, aluno/biblioteca, biblioteca/pesquisa, conhecimento/lazer, entre outros. Sua responsabilidade como mediador é relevante, pois faz uso de seus valores, conhecimentos, crença e pontos de vista nas atividades de seleção, organização, disponibilização do acervo, informações, intervindo nas práticas de leitura e pesquisa no ambiente que atua (BICHERI, 2008). 
Mediação da informação e mediação pedagógica na pesquisa escolar

A interação biblioteca e escola pode ser efetuada em ação conjunta com os professores, uma vez que as pesquisas a serem realizadas fazem parte dos conteúdos programáticos das diversas disciplinas. Martucci (2005, p. 326) apresenta a reflexão de que

[...] o espaço da biblioteca escolar, tradicional projetado e organizado para o consumo de informações constantes em fontes locais e remotas, que hoje incorpora um novo ambiente, específico para a produção de informação: ou seja, um ambiente reservado e apropriado à criação, com computadores, acesso a internet e outros equipamentos periféricos de informática que permitam a digitação de textos, a gravação de sons, a digitalização de imagens, a elaboração de apresentações.

Compreende-se a partir do exposto que quando bem utilizadas, as TIC, aparecem como ótimas ferramentas a favor do ensino e aprendizagem e, consequentemente para pesquisa escolar. Portanto, elas e o seu uso só farão sentido aos alunos no momento em que forem contextualizadas e inseridas de modo consciente na vida escolar deles, visto que será a intencionalidade pedagógica dos profissionais atrelada ao uso das TIC que resultará em aprendizado. Deste modo, evidencia-se a possibilidade e necessidade do ato mediativo na PE.

\section{Mediação na Pesquisa Escolar}

A PE é considerada como tática bastante utilizada por professores e educadores com o intuito de que os alunos, através da pesquisa, adquiram conhecimento sobre o assunto pesquisado e assim melhorem sua aprendizagem. No entanto, Abreu (2002, p. 25) destaca que “[...] na realidade a situação é bem diferente: ninguém está satisfeito com a pesquisa escolar".

Percebe-se no comentário da autora o grau de insatisfação em relação a PE. Pode-se levar isso em consideração, mas sem generalização, devido ao fato da PE não estar sendo levada a sério. A partir de visitas em escolas e do contato com profissionais da área, sabe-se da existência de iniciativas em bibliotecas e escolas que resultam em ótimas pesquisas, como também a formação de alunos, mas é necessário persistir e desenvolver ações para mudar essa prática, ainda presente de diferentes formas no ambiente escolar.

Sendo assim, o envolvimento de mediadores com a intenção de mudar esse quadro buscando interferências diversas é fundamental. Na PE convergem tanto a mediação da informação quanto a mediação pedagógica. Por exemplo: Quando um professor opta pela atividade da PE em sua disciplina, a mediação pedagógica ocorre quando ele explicita aos seus alunos a forma como gostaria que o trabalho fosse realizado, apontando os critérios e as 
Edson Silva Ferreira e João Arlindo dos Santos Neto

condições de avaliação, bem como o modelo de apresentação do mesmo, se apresentação oral ou de trabalho escrito.

O trabalho em conjunto começaria quando o professor comunica ao bibliotecário da escola qual o assunto que será trabalho na PE em sua disciplina e a forma de entrega/apresentação do trabalho.

A mediação da informação por sua vez, aparece neste momento, quando profissional da informação pode se preparar antes e realizar mediações, tanto implícitas quanto explícitas, como na escolha dos melhores materiais em relação ao assunto solicitado pelo professor e os deixando em destaque na $\mathrm{BE}$, no auxílio no momento da realização das pesquisas na internet, em bases de dados ou sites confiáveis e, também, na instrução em relação à formatação e apresentação do trabalho.

A mediação da informação oferece aos mediandos fontes de informação para que eles pesquisem sobre o tema solicitado pelo professor, tornando desta forma a pesquisa mais satisfatória e acompanhada, o que seria muito produtivo. Sobre o assunto em questão, Abreu (2002, p. 25) relatou que em

\footnotetext{
Painel realizado na Escola de Ciência da Informação da Universidade Federal de Minas Gerais, em 1999, com professores e bibliotecários revelou o descontentamento desses profissionais com os rumos que a pesquisa escolar tem tomado nas escolas, hoje em dia. Os professores reclamaram do fato de que alunos simplesmente copiam trechos de enciclopédias. Os bibliotecários queixaram-se de que, por não conhecerem antecipadamente os temas das pesquisas solicitadas, não têm condições de prepararse adequadamente para atender aos alunos que vão em busca de informação geralmente é uma classe inteira procurando um único assunto. Constataram, ainda, que os alunos não sabem o que pesquisar, pois os professores não os orientam efetivamente e não estabelecem, com clareza os objetivos do trabalho. Os bibliotecários observaram que os alunos se mostram confusos quando chegam a biblioteca, ficando evidente que eles não estão satisfeitos.
}

Diante disso, fica evidente a falta de integração entre professor e bibliotecário para propiciar a mediação da informação e a mediação pedagógica na PE. Aos mediadores requerse a criação de circunstâncias para que possam juntos desenvolver estratégias que colaborem de forma significativa com os alunos durante suas pesquisas, independentemente do cenário. Tal posicionamento deixaria explícito aos alunos a preocupação existente nas metodologias e práticas de ensino, bem como ficaria evidente a intencionalidade dos profissionais envolvidos com a aprendizagem dos alunos.

As convergências entre mediação da informação e mediação pedagógica são percebidas no momento em que ambas as práticas são ações que visam a apropriação de informação e a 
construção de conhecimento por parte dos alunos. Já as divergências podem ser reconhecidas a partir do sujeito responsável por cada uma delas, sendo o bibliotecário responsável pela primeira e, o professor, pela segunda.

Elaborou-se a seguir, um quadro com as possibilidades de mediação da informação e mediação pedagógica realizadas tanto pelo professor quanto pelo bibliotecário no processo da PE.

Quadro 1 - Possibilidades de mediação da informação e mediação pedagógica na PE

\begin{tabular}{|c|c|c|}
\hline & $\begin{array}{l}\text { MEDIAÇÃO DA } \\
\text { INFORMAÇÃO }\end{array}$ & MEDIAÇÃO PEDAGÓGICA \\
\hline BIBLIOTECÁRIO & $\begin{array}{l}\text { - Seleciona os melhores itens para } \\
\text { consulta em relação ao tema da } \\
\text { PE; } \\
\text { - Indica leituras; } \\
\text { - Instrui na PE; } \\
\text { - Auxilia a elaboração do } \\
\text { trabalho. }\end{array}$ & $\begin{array}{l}\text { - Comunica a importância do uso } \\
\text { de fontes de informação } \\
\text { confiáveis; } \\
\text { - Expõe os prejuízos que o plágio } \\
\text { pode acarretar; } \\
\text { - Apresenta o mundo da leitura e } \\
\text { do conhecimento. }\end{array}$ \\
\hline PROFESSOR & $\begin{array}{l}\text { - Indica leituras; } \\
\text { - Explica o que é qual o objetivo } \\
\text { da PE; } \\
\text { - Propicia a apropriação da } \\
\text { informação aos alunos a partir } \\
\text { de suas ações. }\end{array}$ & $\begin{array}{l}\text { - Explicita os conteúdos em sala; } \\
\text { - Usa diferentes recursos para o } \\
\text { ensino; } \\
\text { - Expõe os critérios e condições } \\
\text { para a PE. }\end{array}$ \\
\hline
\end{tabular}

Reconhece-se uma linha tênue entre a distinção das práticas de mediação da informação e de mediação pedagógicas. São fazeres integrados e, muitas vezes, necessitam uma da outra para sua concretização. Ressalta-se também que as possibilidades indicadas no quadro 1 não são definitivas e conclusivas em si.

Diante disso percebe-se que ações colaborativas são um meio de mediação na escola. Uma dessas ações seria o trabalho de forma interdisciplinar, ou seja, fazer a integração de outras disciplinas e profissionais de outras áreas realizando assim uma mediação compartilhada. A seguir, apresentam-se os procedimentos metodológicos da pesquisa. 


\section{Procedimentos Metodológicos}

A pesquisa possui caráter exploratório, com abordagem quali-quantitativa. O problema desta pesquisa foi verificar e analisar como ocorre a mediação da informação e a mediação pedagógica em um colégio estadual de Londrina/PR. O trabalho valeu-se de uma revisão bibliográfica inicialmente e posteriormente de uma coleta de dados a duas populações distintas. Primeiro aos alunos do ensino médio e segundo aos professores desses alunos.

Para a coleta de dados da pesquisa utilizou-se como instrumento o questionário com 12 questões abertas e fechadas. As questões de ambos os questionários buscaram descobrir como a mediação da informação e a mediação pedagógica são trabalhadas na escola. Aos alunos questionou-se: a forma como os professores solicitam a entrega dos trabalhos; a fonte de informação mais utilizada para a realização da PE; a existência da preocupação em verificar a veracidade dessas fontes, em especial daquelas disponíveis na internet; se é solicitado que os trabalhos estejam de acordo com as normas da ABNT; se possuem dificuldades em formatar um trabalho e como têm realizado essa atividade; se recebem orientação/instrução do professor/bibliotecário para a realização do mesmo.

Aos professores, as questões procuraram saber se: exigem dos alunos um modelo para entrega dos trabalhos, como por exemplo, que estejam nas normas da ABNT; se verificam com o bibliotecário a existência de material relacionado ao conteúdo proposto na PE; consultam a disponibilidade do bibliotecário em receber os alunos e auxiliá-los no trabalho; consideram importante a presença de um bibliotecário na biblioteca da escola; acreditam que a mediação da informação e a mediação pedagógica auxiliam no desenvolvimento do aluno e já o preparam para o ingresso no ensino superior; conhecem fontes de informação (impressas ou eletrônicas) referentes ao conteúdo de sua disciplina e levam em conta critérios de avaliação no momento da escolha dessas fontes.

Após a coleta foi realizada uma comparação entre as respostas obtidas por essas duas populações. O questionário foi aplicado a um total de 87 alunos e a 15 professores. A população respondente da pesquisa é caracterizada por 32 alunos do $1^{\circ}$ ano, 25 alunos do $2^{\circ}$ ano e 30 alunos do $3^{\circ}$ ano do ensino médio e 15 professores que ministram disciplinas a esses alunos.

Utilizou-se como método de análise, a categorização dos dados, influenciada pela técnica da Análise de Conteúdo de Bardin (2004). As respostas foram categorizadas de acordo 
com sua proximidade e uso de termos iguais ou relacionados. A seguir apresenta-se os resultados e a discussão dos dados obtidos na pesquisa.

\section{Resultados e discussão}

Ao questionar aos alunos a forma como os professores solicitam a entrega dos trabalhos, $67 \%$ dos alunos afirmaram ser no formato escrito (digitado ou a mão) e de seminários. Quando verificada a fonte de informação mais utilizada para a realização da PE, $80 \%$ dos alunos afirmou ser a internet, $15 \%$ indicaram os livros didáticos e $5 \%$ não mencionaram a fonte. Em relação a existência da preocupação em verificar a veracidade dessas fontes, em especial daquelas disponíveis na internet, $42 \%$ afirmaram que comparam com outras fontes de informação na internet, $14 \%$ com os livros didáticos, $8 \%$ avaliam os comentários dos sites e $14 \%$ verificam com o conteúdo visto em sala de aula.

Quando questionado se é solicitado que os trabalhos estejam de acordo com as normas da ABNT, $85 \%$ disseram que sim e os outros $15 \%$ afirmaram que às vezes é solicitado. Em relação às dificuldades dos alunos em formatar um trabalho 66\% deles afirmaram não ter nenhuma dificuldade e $34 \%$ relataram que às vezes possuem. Nesse questionamento foi possível verificar também que as dificuldades vão diminuindo conforme o ano da série vai aumentando, ou seja, os alunos do $1^{\circ}$ ano apresentam mais dificuldades em relação aos do $3^{\circ}$ ano.

Quando perguntado como eles têm realizado a formatação dos trabalhos acadêmicos, os alunos referiram-se mais a forma como elaboram a capa dos trabalhos, 79\% indicaram que colocam os seguintes elementos na capa: nome do colégio, título do trabalho, nome do aluno, turma e data. Os demais, sendo $21 \%$, afirmaram inserir somente: nome do aluno, $\mathrm{n}^{\circ}$ de chamada e o assunto do trabalho. Ao verificar se eles recebem orientação/instrução do professor/bibliotecário para a realização do trabalho, $54 \%$ disseram que às vezes recebe, $23 \%$ afirmaram que sempre recebe e $23 \%$ dos alunos relataram que não recebe nenhuma orientação.

A partir das respostas explicitadas pelos alunos, constata-se que a mediação pedagógica realizada pelos professores poderia ser mais explorada, visto que em vários momentos os alunos apresentam respostas divergentes e falta de instrução em determinadas atividades. 
Quanto às perguntas realizadas aos professores da escola, inicia-se a análise com o seguinte questionamento: Se exigem dos alunos um modelo para entrega dos trabalhos, como por exemplo, que estejam nas normas da ABNT. Do total, $60 \%$ afirmaram que exigem trabalhos de acordo com as Normas e $40 \%$ disseram não exigir. Ao verificar se os professores entram em contato com o bibliotecário para saber da existência de material relacionado ao conteúdo proposto na PE, 33\% afirmaram que verificam, 40\% disseram que não e 27\% relataram as vezes contatar o bibliotecário.

Em relação à consulta da disponibilidade do bibliotecário em receber os alunos e auxiliálos no trabalho, $27 \%$ disseram que verifica, $46 \%$ afirmaram nunca verificar e $27 \%$ relataram que às vezes procura saber se o bibliotecário estará disponível. Ao questionar se os professores consideram importante a presença de um bibliotecário na biblioteca da escola, 80\% afirmaram ser de muita valia, $13 \%$ disseram que sim e 7\% julgam ter importância média. A maioria dos respondentes afirmou que valoriza esse profissional principalmente na orientação bibliográfica, para os professores, o bibliotecário pode contribuir nesta atividade por conhecer quais fontes e materiais são bons para uma pesquisa. Por outro lado, os professores também ressaltaram que o bibliotecário tem conhecimento da organização e da disposição dos materiais da biblioteca.

Quanto ao conhecimento de fontes de informação (impressas ou eletrônicas) referentes ao conteúdo de sua disciplina e se levam em conta critérios de avaliação no momento da escolha dessas fontes, $85 \%$ relatou conhecer e $15 \%$ não. Nessa questão todos os professores responderam que avaliam as fontes a partir de alguns critérios, porém não discursaram sobre eles. No intuito de descobrir se os professores acreditam que a mediação da informação e a mediação pedagógica auxiliam no desenvolvimento e crescimento do aluno e, também, já o preparam para o ingresso no ensino superior, todos os professores relataram acreditar nessa hipótese. No entanto, constata-se pouco envolvimento entre os profissionais e que nem sempre professores medeiam pedagogicamente a pesquisa escolar. 


\section{Conclusões}

A relação entre a mediação e o fazer dos profissionais (bibliotecário/professor) na escola e na pesquisa escolar é necessária no momento em que os professores constaram a importância e a necessidade do bibliotecário na escola. Foi investigado se os professores atuam em conjunto com os bibliotecários, desenvolvendo a mediação nas pesquisas escolares. De acordo com a revisão bibliográfica deste artigo, infere-se que a mediação informacional e pedagógica dos professores e bibliotecários interfere de forma positiva nas pesquisas escolares. No entanto, diante dos resultados desta pesquisa ficou evidente que professores e bibliotecário na escola pesquisada, interagem pouco ou quase nada. Esta falta de interação impacta diretamente no resultado das pesquisas escolares.

A mediação pedagógica foi percebida de maneira tímida e ainda superficial, se relacionada a PE, a mediação da informação parece também não ocorrer de maneira expressiva. Os alunos, na maioria dos questionamentos apontam que há uma divergência entre a maneira que os trabalhos escolares são requeridos pelos professores. Os professores por sua vez, mesmo elucidando a importância do bibliotecário, interagem pouco com ele e não o insere em suas práticas pedagógicas.

Conclui-se que o bibliotecário escolar pode realizar a mediação da informação quando: seleciona os melhores itens para consulta em relação ao tema da PE; indica leituras aos alunos; instrui no desenvolvimento e na execução da PE; auxilia na elaboração e no formato de apresentação do trabalho.

Realiza a mediação pedagógica a partir do momento que: comunica a importância do uso de fontes de informação confiáveis e da comparação delas com outras fontes; expõe os prejuízos que o plágio pode acarretar ao aluno, deixando claro a ele que o método $C t r l+c$ e $C r t l+v$ tão recorrente na PE interfere no processo de aprendizagem e, apresenta o mundo da leitura e do conhecimento ao aluno.

O professor por sua vez, realiza mediação da informação ao: Indicar leituras de acordo com a temática trabalhada; explicar o que é qual o objetivo da PE; propiciar a apropriação da informação aos alunos a partir de suas ações. Pratica a mediação pedagógica quando: explicita os conteúdos em sala; usa diferentes recursos para o ensino e, expõe os critérios e condições para a PE. 
Constata-se ainda pouca mediação pedagógica e da informação nas pesquisas escolares, defende-se que essa prática deveria ser mais explorada pelos profissionais envolvidos na Educação. É preciso que professores bibliotecários estabeleçam estratégias que permitam fazer um trabalho de mediação, tanto pedagógica quanto informacional.

\section{Referências}

ABREU, V. L. F. G. Pesquisa escolar. In: CAMPELLO, B. S. et al. A biblioteca escolar: temas para uma pratica pedagógica. Belo Horizonte: Autêntica, 2002. p. 25-28.

ALMEIDA JÚNIOR, O. F. Mediação da informação: ampliando o conceito de disseminação. In: VALENTIM, M. L. P. (Org.). Gestão da informação e do conhecimento. São Paulo: Polis; Cultura Acadêmica, 2008. p.41-54.

. Mediação da informação: um conceito atualizado. In: BORTOLIN, S.; SANTOS NETO, J. A.; SILVA, R. J. (Org.). Mediação oral da informação e da leitura. Londrina: Abecin, 2015. p. 9-32.

BARDIN, L. Análise de conteúdo. 3.ed. Lisboa: 70, 2004.

BICHERI, A. L. A. O. A mediação do bibliotecário na pesquisa escolar face a crescente virtualização da informação. 2008. 197f. Dissertação (Mestrado em Ciência da Informação) - Universidade Estadual Paulista, Marília, 2008. Disponível em:

$<$ http://www.marilia.unesp.br/Home/Pos-

Graduacao/CienciadaInformacao/Dissertacoes/bicheri_alao_me_mar.pdf > . Acesso em: 08 maio 2014.

BORTOLIN, S. A leitura e o prazer de estar na biblioteca escolar. In: SILVA, R. J.;

BORTOLIN, S. (Org.). Fazeres cotidianos da biblioteca escolar. São Paulo: Polis, 2006. p. 65-72.

BRASIL. Lei $\mathrm{n}^{\circ}$ 12.244, de 24 de maio de 2010. Dispõe sobre a universalização das bibliotecas nas instituições de ensino do País. Diário oficial da união, Brasília, DF, 24 maio 2010. Disponível em: <http://www.planalto.gov.br/ccivil_03/_Ato20072010/2010/Lei/L12244.htm>. Acesso em: 12 maio 2015.

Ministério da Educação. Secretaria de educação básica. Programa Nacional Biblioteca da Escola (PNBE): leitura e bibliotecas nas escolas públicas brasileiras. Brasília: Ministério da Educação, 2008. Disponível em:

〈http://portal.mec.gov.br/seb/arquivos/pdf/Avalmat/livro_mec_final_baixa.pdf>. Acesso em: 04 mar. 2016.

CAMPELLO, B. S. Letramento informacional: função educativa do bibliotecário na escola. Belo Horizonte: Autêntica, 2009. 
Biblioteca escolar: conhecimentos que sustentam a prática. Belo Horizonte:

Autêntica, 2012.

DAVAllon, J. A mediação: a comunicação em processo?. Prisma.com, n. 4, p. 3-36, jun. 2007. Disponível em: 〈http://revistas.ua.pt/index.php/prismacom/article/view/645/pdf〉. Acesso em: 22 maio 2015.

ELLWEIN, S. A. F. Pesquisa escolar e o enfadonho exercício de cópia: como separar o trigo do joio. In: SILVA, R. J.; BORTOLIN, S. (Org.). Fazeres cotidianos da biblioteca escolar. São Paulo: Polis, 2006, p. 79-96.

FREIRE, P. Pedagogia da autonomia: saberes necessários à prática educativa. São Paulo: Paz e Terra, 2011.

GOMES, H. F. A dimensão dialógica, estética, formativa e ética da mediação da informação. Informação \& Informação, Londrina, v. 19, n. 2, p. 46-59, out. 2014. Disponível em: <http://www.uel.br/revistas/uel/index.php/informacao/article/view/19994>. Acesso em: 07 out. 2015.

IFLA. Manifesto IFLA/ UNESCO para biblioteca escolar. São Paulo, 2002. Disponível em: <http://www.ifla.org/VII/s11/pubs/portuguesebrasil.pdf>. Acesso em: 13 maio 2015.

KUHLTHAU, C. Como usar a biblioteca na escola: um programa de atividades para o ensino fundamental. Belo Horizonte: Autêntica, 2002.

LIBÂNEO, J. C. Os campos contemporâneos da didática e do currículo: aproximações e diferenças. 2002. Disponível em:

<https://ead.ufrgs.br/rooda/aulas/abrirArquivo.php/turmas/3184/atividades/9099/texto1_camp os_contemporaneos_didatica_curriculo.htm>. Acesso em: 22 ago. 2015.

MARTUCCI, E. M. Recursos informativos-acervo: debatedores. In: MACEDO, N. D. (Org.). Biblioteca escolar brasileira em debate: memória profissional a um fórum virtual. São Paulo: SENAC/CRB8, 2005. p. 323- 326.

MASETTO, M. T. Mediação pedagógica e o uso da tecnologia. In: MORAN, J. M.; MASETTO, M. T; BECHRENS, M. A. Novas tecnologias e mediação pedagógica. Campinas: Papirus, 2000. p. 133-173.

SISTEMA CFB/CRB. Biblioteca escolar construção de uma rede de informação para o ensino público. Brasília, 2008. Disponível em:

<http://www.cfb.org.br/UserFiles/File/promobil/PROMOBILFINAL.pdf>. Acesso em: 17 maio 2015.

SOUZA, A. M. M.; DEPRESBITERES, L.; MACHADO, O. T. M. A mediação como princípio educacional: bases teóricas das abordagens de Reuven Feuerstein. São Paulo: Senac, 2004.

TAVARES, D. F. A biblioteca escolar. Brasília: INL, 1973. 